\title{
Choice for Drug or Natural Reward Engages Largely Overlapping Neuronal Ensembles in the Infralimbic Prefrontal Cortex
}

\author{
Simone Pfarr, ${ }^{1}$ Laura Schaaf, ${ }^{1}$ Janine K. Reinert, ${ }^{2}$-Elisabeth Paul, ${ }^{1}$ Frank Herrmannsdörfer, ${ }^{2}$ Martin Roßmanith, ${ }^{1}$

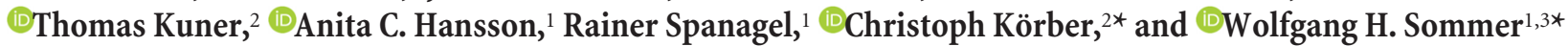 \\ ${ }^{1}$ Institute of Psychopharmacology, ${ }^{3}$ Addiction Medicine, Central Institute of Mental Health, Medical Faculty Mannheim, University of Heidelberg, 68159 Mannheim, \\ Germany, and ${ }^{2}$ Institute of Anatomy and Cell Biology, Department of Functional Neuroanatomy, Heidelberg University, 69120 Heidelberg, Germany
}

Cue-reward associations form distinct memories that can drive appetitive behaviors and are involved in craving for both drugs and natural rewards. Distinct sets of neurons, so-called neuronal ensembles, in the infralimbic area (IL) of the medial prefrontal cortex (mPFC) play a key role in alcohol seeking. Whether this ensemble is specific for alcohol or controls reward seeking in general remains unclear. Here, we compared IL ensembles formed upon recall of drug (alcohol) or natural reward (saccharin) memories in male Wistar rats. Using an experimental framework that allows identification of two distinct reward-associated ensembles within the same animal, we found that cue-induced seeking of either alcohol or saccharin activated ensembles of similar size and organization, whereby these ensembles consist of largely overlapping neuronal populations. Thus, the IL seems to act as a general integration hub for reward seeking behavior, but also contains subsets of neurons that encode for the different rewards.

Key words: conditioned cues; fos; medial prefrontal cortex; neuronal ensembles; reinstatement; reward-seeking behavior

\section{Significance Statement}

Cue-reward associations form distinct memories that can act as drivers of appetitive behaviors and are involved in craving for natural rewards as well as for drugs. Distinct sets of neurons, so-called neuronal ensembles, in the infralimbic area of the mPFC play a key role in cue-triggered reward seeking. However, it is unclear whether these ensembles act as broadly tuned controllers of approach behavior or represent the learned associations between specific cues and rewards. Using an experimental framework that allows identification of two distinct reward-associated ensembles within the same animal we find largely overlapping neuronal populations. Repeated activation by two distinct events could reflect the linking of the two memory traces within the same neuron.

\section{Introduction}

Drinking a beer or rather a cola, we commonly face concurrent options to satisfy our needs and desires, and decide based on experience and actual context. However, when such choices

Received Jan. 5, 2018; revised Feb. 4, 2018; accepted Feb. 9, 2018.

Author contributions: S.P., A.C.H., R.S., C.K., and W.H.S. designed research; S.P., L.S., E.P., M.R., and C.K. performed research; F.H. and T.K. contributed unpublished reagents/analytic tools; S.P., L.S., J.K.R., E.P., and C.K. analyzed data; S.P., C.K., and W.H.S. wrote the paper.

This work was supported by Deutsche Forschungsgemeinschaft Center Grants SFB1134 subprojects A04 to C.K. and T.K., B04 to W.H.S. and T.K., and B05 to R.S. and A.C.H., and the European Union's Horizon 2020 program 668863-SyBil-AA. We thank Marion Schmitt, Elisabeth Röbel, Janet Barroso-Flores, Ana Gallego Romàn, Rebecca Hoffmann, Valentina Vengeliene, and Thorsten Lau for technical assistance.

The authors declare no competing financial interests.

${ }^{*}$ C.K. and W.H.S. contributed equally to this work.

Correspondence should be addressed to either of the following: Dr. Wolfgang H. Sommer, Central Institute of Mental Health, Square J5, 68159 Mannheim, Germany, E-mail: wolfgang.sommer@zi-mannheim.de; or Dr. Christoph Körber, Heidelberg University, INF 307, 69120 Heidelberg, Germany, E-mail: koerber@ana.uni-heidelberg.de. DOI:10.1523/JNEUROSCI.0026-18.2018

Copyright $\odot 2018$ the authors $\quad 0270-6474 / 18 / 383507-13 \$ 15.00 / 0$ become strongly biased, individuals may risk severe long-term consequences, for example, developing addiction or substance use disorders, accounting for a large proportion of global disease burden (Whiteford et al., 2013). Despite this high burden on the health care system, little is known about the neurobiological mechanisms underlying the processing of concurrent reward options in the brain.

Responses toward appetitive stimuli, including natural and drug rewards, are prototypical learned behaviors, whereby previously neutral cues and contexts that are repeatedly paired to reward consumption acquire incentive-motivational properties (Flagel et al., 2009). Associative learning can be studied using operant conditioning, where subjects learn to discriminate between two options: responding at one lever is associated with reward delivery, whereas responding at another lever is not (Sanchis-Segura and Spanagel, 2006; Martin-Fardon and Weiss, 2013). The neuronal responses to appetitive reward associated stimuli are widely studied in the context of craving, a phenomenon often reported by indi- 
viduals suffering from an addiction, and recently included into the Diagnostic and statistical manual of mental disorders (DSM5.0) as a criterion for alcohol and substance use disorders (American Psychiatric Association, 2013). Interestingly, a comprehensive meta-analysis of functional neuroimaging experiments on cue responsivity to natural and drug stimuli in humans found largely overlapping activated neural substrates, including the mPFC (Noori et al., 2016). Similarly, functional neuroimaging in rats found widely shared neuronal networks recruited by alcohol and saccharin rewards (Dudek et al., 2015).

The mPFC is involved in executive functions (e.g., self-control, value attribution, and decision making) both in rodents and primates, and plays a key role in the control of associative reward conditioning (Heidbreder and Groenewegen, 2003; Wood and Grafman, 2003; Dalley et al., 2004; Rushworth et al., 2011). It is also particularly sensitive to alcohol-induced long-term damage (Zahr et al., 2011; Meinhardt et al., 2013; Heilig et al., 2017). Within the mPFC, memories about specific contingencies of reward availability are thought to be physically allocated to neuronal ensembles (Suto et al., 2016). These engrams in discrete and sparse neuronal populations show coordinated spatiotemporal activity that can be reliable reactivated upon recall (Hebb, 1949; Tonegawa et al., 2015; Holtmaat and Caroni, 2016). Neuronal ensembles can be identified in vivo via the neuronal activity marker cFos (Morgan and Curran, 1991; Cruz et al., 2013). Previous research demonstrated a causal link of a neuronal ensemble in the infralimbic subregion (IL) of the MPFC with conditioned alcohol seeking by chemogenetic ablation of cFos-responsive neurons (Pfarr et al., 2015). Similar ensembles have been identified for cue- or context-induced seeking of other drug or natural rewards (Bossert et al., 2011; Cruz et al., 2015; Pfarr et al., 2015; Suto et al., 2016; Warren et al., 2016), but different experimental procedures make a comparison of these studies difficult. It thus remains elusive whether different reward-paired cues recruit different neuronal ensembles in the IL or whether the activated ensembles are, at least partially, overlapping.

Here, we compare IL neuronal ensembles engaged in drug and natural reward seeking. Toward this aim, we developed a new concurrent operant self-administration protocol for two different rewards: alcohol as a drug and a sweet saccharin solution as a natural reward. This procedure enables direct comparison of cueinduced neuronal ensembles within the same animal, whereby distinction of two separately activated cell populations in the rat brain was achieved using double-cFos mRNA FISH method for the simultaneous detection of different $c F o s$ isoforms. We found that alcohol- and saccharin-associated cues engage largely overlapping $\mathrm{cFos}^{+}$neuronal ensembles of similar size and organization. Our results support the hypothesis that within the IL two distinct memory traces are maintained in discrete populations of neurons. However, both memory traces are strongly linked via encoding in overlapping ensembles.

\section{Materials and Methods \\ Animals}

A total of 72 male Wistar rats (Charles River, initial weight 250-300 g) were used in the experiments. The rats were housed in groups of 4 under a $12 \mathrm{~h} \mathrm{light/dark} \mathrm{cycle} \mathrm{with} \mathrm{food} \mathrm{and} \mathrm{water} \mathrm{available} \mathrm{ad} \mathrm{libitum} \mathrm{in} \mathrm{the}$ home cages. Behavioral testing was performed during the dark phase of the light/dark cycle from 6:00 A.M. to 6:00 P.M., 5 d per week. All experiments were conducted in accordance with the European Union guidelines for the care and use of laboratory animals and were approved by the local animal care committee (Regierungspräsidium Karlsruhe, Karlsruhe, Germany).

\section{Experimental design}

Male Wistar rats were trained on an operant training protocol to concurrently self-administer $10 \%(\mathrm{v} / \mathrm{v})$ ethanol or saccharin (SigmaAldrich) solutions. To yield similar numbers of lever presses for both rewards, the concentration of the saccharin solution was adjusted in the different experiments to match the average performance on the alcohol lever for each batch of animals. After reaching comparable baseline response rates for both rewards, animals underwent a progressive ratio (PR) schedule (Hodos, 1961) to test their motivation for ethanol and saccharin. This was followed by random self-administration sessions for ethanol and saccharin until a stable baseline was reached. Then, all animals underwent five extinction sessions and one cue-induced reinstatement session for each reward separated by $3 \mathrm{~d}$ in a counterbalanced manner (see Figs. 1A, 2A, 3A).

\section{Behavioral procedures}

Operant conditioning training. All reward-seeking experiments were performed in standard operant chambers (MED Associates) enclosed in ventilated sound-attenuating cubicles as described previously (Meinhardt et al., 2013; Pfarr et al., 2015). In brief, responses at the appropriate (active) lever led to the delivery of $\sim 30 \mu \mathrm{l}$ of reward (ethanol or saccharin solution), presented in a liquid receptacle next to the lever. Correct lever responses activated a light stimulus placed above the response lever. Ethanol and saccharin self-administration training and testing sessions were performed $3 \mathrm{~h}$ after beginning of the dark phase of the light/dark cycle at $5 \mathrm{~d}$ per week (Sanchis-Segura and Spanagel, 2006). Animals were trained to self-administer $10 \%(\mathrm{v} / \mathrm{v})$ ethanol in daily $30 \mathrm{~min}$ sessions without prior sucrose- or saccharin-fading procedures. During the first $3 \mathrm{~d}$ of training, the animals were kept water-deprived for $18 \mathrm{~h}$ per day. The animals were trained to associate the availability of ethanol with the presence of specific discriminative stimuli, using a combination of discriminative (olfactory) and contingent (visual) cues (Ciccocioppo et al., 2002, 2003; Meinhardt et al., 2013; Pfarr et al., 2015). Two odors (orange oleum Aurantii Dulcis g420; lemon grass oil w861, Caelo) served as olfactory contextual stimuli to predict the presence of ethanol and saccharin, respectively. Four to six drops of either pure odor solution were applied to the bedding material of the operant chamber before the start of each session, ensuring the presence of the stimulus throughout the whole session. In addition, a discrete visual stimulus ( $5 \mathrm{~s}$ blinking light) was presented after responses at the correct, rewarded lever (ethanol $=$ left lever and left cue-light, saccharin = right lever and right cue-light). The $5 \mathrm{~s}$ period of blinking light presentation served as a "time out," during which responses were recorded but did not lead to reward delivery. All animals underwent 9 ethanol training sessions, during which only the active lever was presented. During the following 4 training sessions, the inactive lever was also presented and the animals learned to discriminate between active and inactive lever for the ethanol-associated cues. The same procedure was repeated for saccharin cue-conditioning.

$P R$ test. Following acquisition of concurrent ethanol and saccharin self-administration, the animals' motivation to self-administer ethanol $(\mathrm{EtOH})$ and saccharin was tested on a $30 \mathrm{~min}$ PR schedule. Under these conditions, an increasing number of lever presses during one trial $(1,2,4$, $6,8,10,12,14 \ldots)$ was required to receive 1 drop of either $10 \%(\mathrm{v} / \mathrm{v})$ EtOH or $0.025 \%(w / v)$ saccharin solution (Richardson and Roberts, 1996). Trials were aborted if the animals stopped responding for $2 \mathrm{~min}$. PR tests were performed with both rewards in a counterbalanced design in two independent sessions separated by $3 \mathrm{~d}$. The breakpoint was calculated using the highest completed response requirement during the 30 min PR session.

Self-administration baseline and extinction training. All animals underwent 8 randomized concurrent self-administration sessions to reach a stable baseline for each reward. Thereafter, all animals were subjected to daily extinction sessions ( $30 \mathrm{~min}$ ) for $5 \mathrm{~d}$. This was sufficient to reach an extinction criterion of $<10 \%$ of baseline activity at the active lever per session. During extinction sessions, both levers were available without presentation of the olfactory conditioned stimuli. Responses at the previously active lever activated the respective syringe pump, which, however, did not result in reward delivery or presentation of the discrete visual conditioned stimulus (blinking light). 
Cue-induced reinstatement test. The animals were presented with the same conditioned stimuli as during the conditioning phase. Responses at the active lever resulted in the presentation of the visual conditioned stimulus and activation of the syringe pump, but not in reward delivery. Reinstatement for both rewards was performed in two independent sessions separated by $3 \mathrm{~d}$. Next, the animals were subjected to additional reinstatement sessions without further training sessions (see Figs. 2A, $3 A$ ). Of note, in Experiment 2, the last two reinstatement sessions were only $5 \mathrm{~min}$ long and separated by $30 \mathrm{~min}$ (see Fig. $3 A$ ). In a previous study (Pfarr et al., 2015), we have demonstrated that rats can successfully perform several consecutive cue-induced reinstatement tests over a period of 2 weeks without noticeable extinction of behavioral responding.

\section{Stereotaxic surgery and retrograde tracing}

A total of 28 Wistar rats from Experiment 1 were stereotaxically injected with the retrograde tracer cholera toxin $\mathrm{B}$ coupled to fluorescent dyes Alexa-488 and Alexa-647 (Thermo Fisher). Animals were anesthetized with isoflurane and mounted in a stereotaxic frame (David Kopf Instruments). Approximately $1 \mu$ l of cholera toxin B solution ( $1 \mathrm{mg} / \mathrm{ml}$ in PBS) was injected into two of the following target regions using the denoted coordinates relative to bregma and midline (anteroposterior, mediolateral, dorsoventral, $\mathrm{mm}$ as follows): prelimbic area (PrL), $3, \pm 0.5 \mathrm{~mm}$, -4 ; IL, 3, $\pm 0.5,-5.5$; NAc, $1.6, \pm 0.9,-7.5$; VTA, $-5.3, \pm 0.8,-9.5$. Animals recovered from anesthesia within minutes and were maintained group housed to recover for $5 \mathrm{~d}$ before further behavioral testing. Injection sites were verified postmortem using a DM6000B microscope (Leica Microsystems) equipped with a $10 \times$ HC PL APO dry objective (NA: 0.4).

\section{Immunohistochemistry}

Animals were transcardially perfused with $100 \mathrm{ml}$ PBS followed by $100 \mathrm{ml}$ of 4\% PFA in PBS, 90 min after the beginning of the final cueinduced reinstatement sessions, the time point of maximal cFos protein expression (Sheng and Greenberg, 1990). Brains were removed and postfixed overnight at $4^{\circ} \mathrm{C}$ in fixative solution (4\% PFA in PBS). PFA was removed by 3 washes in PBS before the brain was cut into $70-\mu \mathrm{m}$-thick slices on a vibratome (VT1000S, Leica Microsystems). Slices were stored in cryoprotectant solution $(1 \times$ phosphate buffer: $40 \%(\mathrm{v} / \mathrm{v})$, glycerole: $30 \%(\mathrm{v} / \mathrm{v})$, ethylene glycol: $30 \%(\mathrm{v} / \mathrm{v})$ at $-20^{\circ} \mathrm{C}$ until further usage.

Antibody stainings were performed on cryoprotected, fixed brain slices containing the $\mathrm{mPFC}$. Slices were washed three times in TBS $(0.025 \mathrm{M}$ Tris$\mathrm{Hcl}, 0.5 \mathrm{M} \mathrm{NaCl}$ ) to remove cryoprotectant solution before blocking for $1 \mathrm{~h}$ in TBS supplemented with $0.2 \%$ Triton X-100, 7.5\% normal goat serum, and 2.5\% BSA. Primary antibodies directed against NeuN (Millipore, catalog \#MAB377, RRID:AB_2298772, mouse, monoclonal) and cFos (Cell Signaling Technology, catalog \#2250, RRID:AB_2247211, rabbit, monoclonal) were applied in blocking solution at 1:250 and 1:500 dilutions, respectively. Slices were incubated at $4^{\circ} \mathrm{C}$ overnight and washed three times with TBS. Appropriate Alexa-405- and Alexa-568 dye-coupled secondary antibodies (Thermo Fisher) were applied at 1:1000 dilutions in TBS containing $0.2 \%$ Triton X-100 for $1 \mathrm{~h}$ at room temperature. Finally, slices were rinsed three times with TBS and mounted in Mowiol.

Stained mPFC sections were examined by confocal microscopy using a TCS SP5 microscope (Leica Microsystems) equipped with a $63 \times$ HCX PL APO (1.45 NA) objective. Four image stacks were acquired at random positions in the IL of each hemisphere (image resolution: $512 \times 512$ pixels; voxel size: $0.459 \times 0.459 \times 2.519 \mu \mathrm{m}$; image dimensions: $x, y=$ $234.32 \mu \mathrm{m}, z=2.52 \mu \mathrm{m})$. Three slices were examined per animal.

Data were analyzed in a semiautomated way. Custom-written MATLAB (RRID:SCR_001622, The MathWorks) procedures were used to determine the number of objects recorded in each imaging channel (NeuN, cFos, two tracers) and the number of objects positive for cFos. Therefore, all channels were first smoothed by a 2D Gaussian filter $(\sigma=$ 3 pixels, 1 pixel $=0.459 \mu \mathrm{m}$ ) before the intensities of all channels were binarized. The threshold for the binarization was chosen such that $95 \%$ of the NeuN signal and the $98 \%$ of the cFos signal and of both tracer signals were defined as background pixels. Thresholds were calculated for each frame individually to compensate for decreasing intensities deeper in the tissue. The NeuN signal was eroded by removing two pixels from the edge of the signal. A connected components analysis with a connectivity of 26 was performed for each channel. Connected components that did not reach a certain size ( 500 voxels for NeuN and cFos, 750 voxels for tracer channels) were excluded from analysis as they are likely to not represent true signals. The center of mass of each connected component in each channel was determined. Colocalization between cFos signals and objects in the other three channels was assigned by close proximity analysis (range: $10 \mu \mathrm{m}$ ) based on the centers of mass. The results of the colocalization analysis were confirmed by manual inspection.

\section{FISH}

To distinguish two sets of $\mathrm{cFos}^{+}$neurons triggered by stimuli that are timely separated, we used a double-FISH method that is based on the different temporal profiles of nascent (unspliced) and mature (spliced) cFos mRNA species. Upon a stimulus, cFos mRNA is rapidly induced within a few minutes, but this nascent form has a rapid turnover and is quickly spliced. Thus, in our approach, neurons active during the first reinstatement are labeled by mature $c$ Fos mRNA, whereas those activated by the second reinstatement are marked by nascent $c$ Fos mRNA (Lin et al., 2011).

Rats were rapidly decapitated $5 \mathrm{~min}$ after the last cue-induced reinstatement session, brains were removed, frozen in isopentane $\left(-50^{\circ} \mathrm{C}\right)$, and kept at $-80^{\circ} \mathrm{C}$ until further processing. Brain slices of $20 \mu \mathrm{m}$ thickness were cut on a cryostat and thaw-mounted onto Super Frost Plus slides (Thermo Fisher). FISH analysis was performed using the RNAscope Multiplex Fluorescent Reagent Kit (Advanced Cell Diagnostics; Probes Rn-Fos-O1-C2, Rn-Fos-Intron1-C3, Rn-Bcl11b, and Rn-Rgs8C3) according to the manufacturer's instructions (freshly frozen tissue).

Brain sections containing the $\mathrm{mPFC}$ were examined by confocal microscopy (see above). Three images were acquired at random positions in the IL of each brain slice. Two slices were examined per animal. For layer specific cFos expression, three images were then taken per layer in each brain slice.

Data were analyzed for colocalization of FISH signals in both channels using the cell counter macro of ImageJ (Fiji, RRID:SCR_002285). Specificity of FISH signal was verified by colocalization with DAPI. In case of double labeling for spliced and unspliced $c F o s$ mRNA, the scattered signal pattern prevented semiautomated analysis. This dataset was manually analyzed as follows: first, the fraction of DAPI-positive cells expressing spliced $c F$ os was calculated per animal. Then, expression of unspliced cFos mRNA was measured as mean gray value per cell, based on manually determined regions of interest using ImageJ. To discriminate basal from activity induced expression of unspliced $c F o s$, gray values were ranked and the fraction of cells showing the highest unspliced $c F o s$ mRNA expression, identical to the fraction of spliced cFos mRNA, were used for colocalization analysis as described below.

\section{Statistical analysis}

Data are expressed as mean \pm SEM. Behavioral data were analyzed using two-tailed paired $t$ test or two-way repeated-measures ANOVA followed by Newman-Keul's post hoc test, where appropriate (Statistica 10, RRID: SCR_015627, Statsoft). Animals were excluded from analysis if they either failed to discriminate the active lever during self-administration or they did not show significant ( $>15$ lever presses in $30 \mathrm{~min}$ ) reinstatement behavior in response to either of the cues. Immunohistochemistry and FISH data were analyzed by two-tailed unpaired $t$ test and two-way ANOVA using GraphPad Prism 5 (RRID:SCR_002798). The $\alpha$ level for significant effects was set to 0.05 . In case of colocalization of spliced and unspliced $c$ Fos mRNA, statistical significance of colocalization was tested by shuffle test using custom-written IGOR macros (100,000 repetitions, RRID:SCR_000325, Wavemetrics). Therefore, the thresholded signal of unspliced $c F o s$ (see above) and the signal of mature $c F o$ s were binarized and analyzed for colocalization.

\section{Results}

Setup of concurrent operant self-administration protocol

To directly compare reward-seeking behavior for natural (nondrug) and drug rewards, we established an operant protocol for 
A

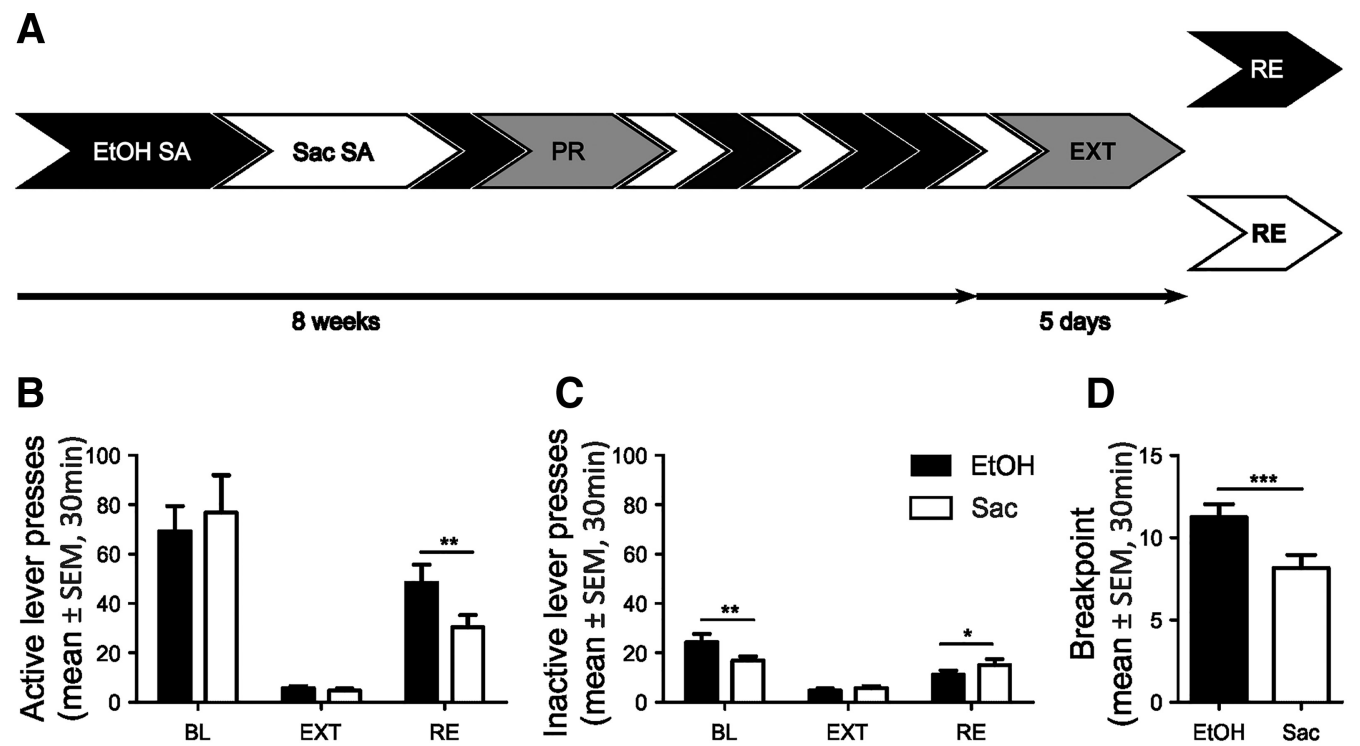

Figure 1. Two-reward operant conditioning task for concurrent alcohol and saccharin seeking. $A$, Timeline for ethanol and saccharin self-administration (SA), progressive ratio (PR), extinction training (EXT), and counterbalanced cue-induced reinstatement (RE) of alcohol (EtOH) and saccharin (Sac) seeking. B, C, Quantification of lever presses during baseline (BL) self-administration, EXT, and RE. D, PR test. ${ }^{*} p<0.05,{ }^{* *} p<0.01,{ }^{* * *} p<0.001 . n=13$. For detailed statistics, see Table 1.

Table 1. Statistics of two-reward operant experiment: results for repeated-measures ANOVA and Newman-Keuls post hoc test ${ }^{a}$

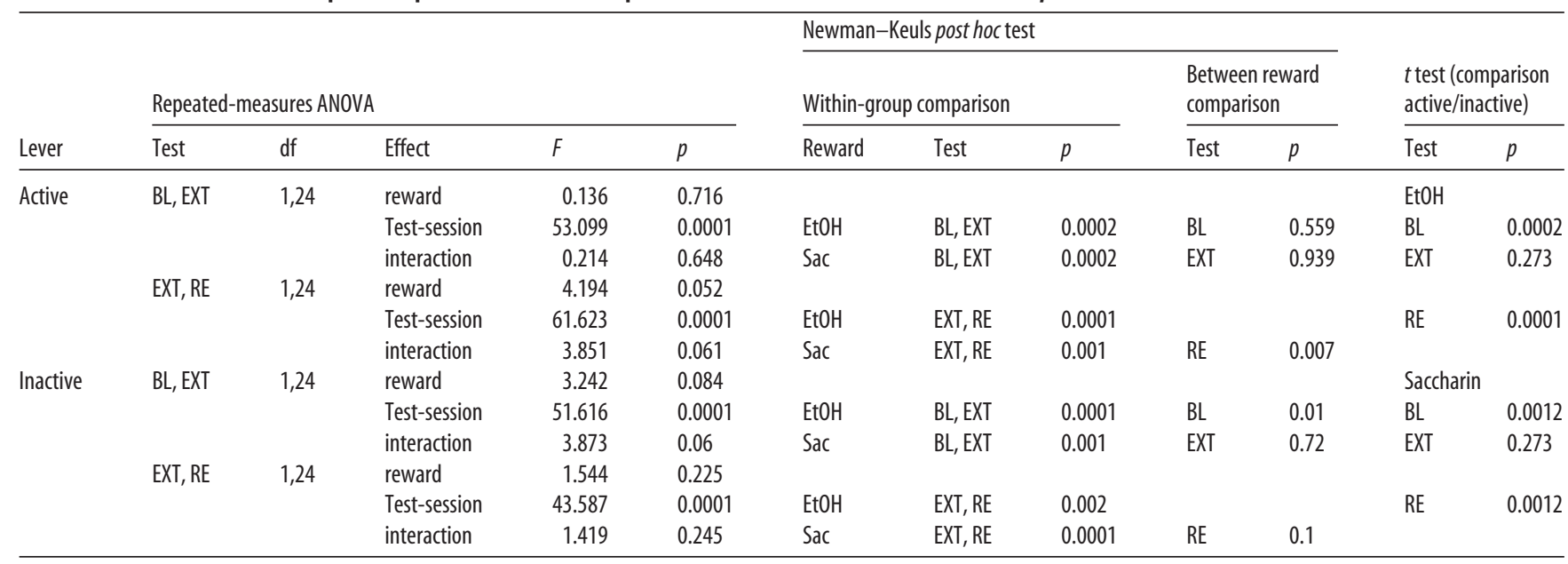

${ }^{a}$ Comparison between active and inactive lever was done using two-tailed paired $t$ test. BL, Self-administration baseline; EXT, extinction; RE, cue-induced reinstatement; EtOH, ethanol; Sac, saccharin.

the concurrent self-administration of EtOH and saccharin solutions (Fig. 1A). Although saccharin is an artificial sweetener, we refer to it as a natural reward due to its sweet taste. After selfadministration training for $10 \%$ alcohol, 16 male Wistar rats were trained to self-administer $0.04 \%$ saccharin solution. Given the high reinforcement value of a standard $0.2 \%$ saccharin solution (in a typical experiment rats can respond $>200$ times per session under a fixed ratio 1 schedule), the concentration was adjusted to match the performance of the rats in the ethanol self-administration sessions, thereby counteracting potential biases in neuronal ensemble properties resulting from mere differences in motor activity. After animals had learned the contingencies for $\mathrm{EtOH}$ and saccharin rewards, their motivation for each reward was tested under a PR schedule (Fig. 1D). Thus, the animals had to make an increasing number of lever responses to receive the same amount of reward. Interestingly, the animals showed a significantly lower breakpoint for saccharin compared with $\mathrm{EtOH}$ $\left(t_{(1,12)}=-4.38, p=0.0009, n=13\right.$, two-tailed paired $t$ test; Fig. $1 D)$, although there was no difference in baseline self-admini- stration between alcohol and saccharin (Fig. $1 B$; for full statistics, see Table 1). This indicates that, despite similar self-administration of both rewards, alcohol is more rewarding. After further alternations between the two rewards, rats continued with extinction training. Five days of extinction training was equally effective for both rewards ( $<10 \%$ of baseline lever presses) with no significant difference between the previously rewarded alcohol- or saccharin-paired levers (Fig. 1B; Table 1). Next, all animals underwent counterbalanced cue-induced reinstatement sessions in which the previously acquired reward-associated conditioning cues (odors) were presented but not rewarded. Successful reinstatement behavior resulted in significantly increased numbers of presses at the previously reward-paired lever (Fig. 1B; Table 1). Three animals were excluded from the analysis because they failed to match the criteria for successful reinstatement $(>15$ lever presses in $30 \mathrm{~min}$ ). Consistent with the PR test, rats pressed significantly more at the alcohol- versus saccharin-paired lever, reflecting the somewhat higher motivation for the $10 \% \mathrm{EtOH}$ solution over the $0.04 \%$ saccharin solution. Rats showed signifi- 


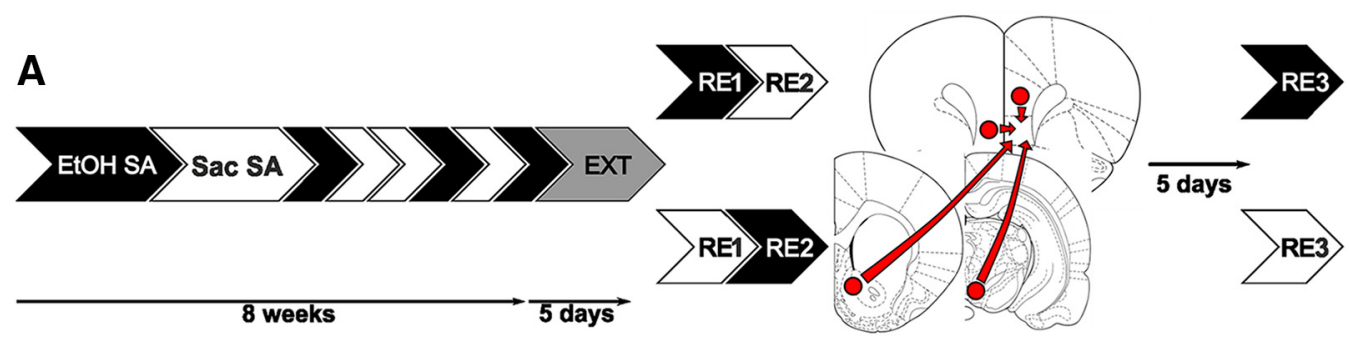

B
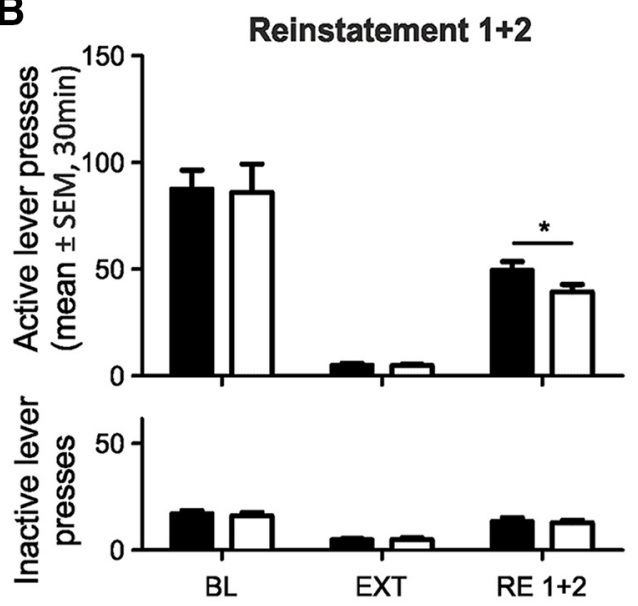

C
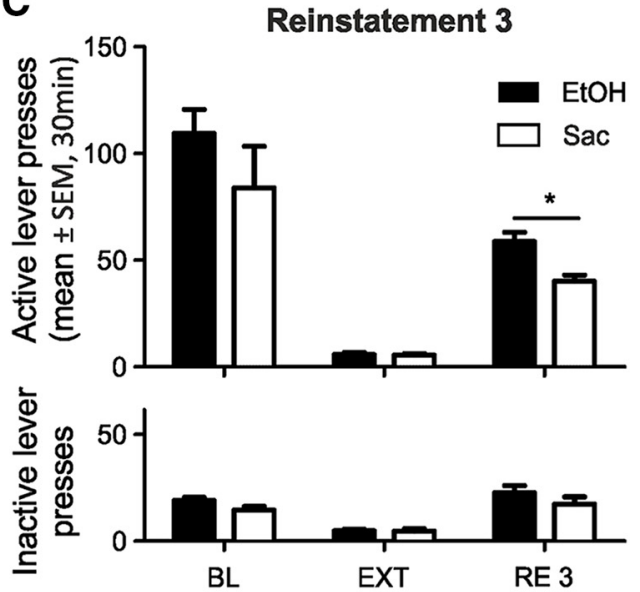

E

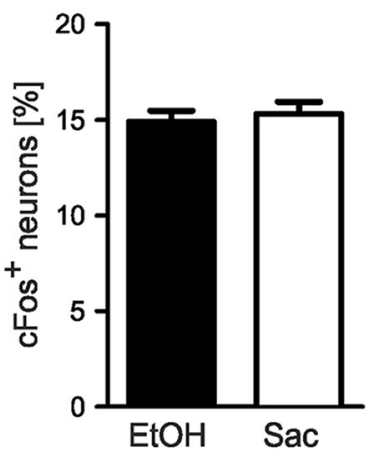

Figure 2. Similar size of IL neuronal ensembles involved in ethanol and saccharin seeking. $\boldsymbol{A}$, Experimental timeline for ethanol (EtOH, black) and saccharin (Sac, white) self-administration (SA), extinction (EXT), counterbalanced cue-induced reinstatement (RE1 + 2) of ethanol, and saccharin seeking, followed by retrograde tracer injections and the final cue-induced reinstatement for either ethanol or saccharin (RE3). $\boldsymbol{B}, \boldsymbol{C}$, Active and inactive lever presses for ethanol and saccharin self-administration baseline (BL), EXT and RE $(\boldsymbol{B})$ RE1 +2 ( $n=28)$, and $(\boldsymbol{C})$ RE3 ( $n=14 /$ reward). $\boldsymbol{D}$, Representative images of NeuN and cFos immuno double-labeling in the IL after ethanol and saccharin reinstatement (RE3). Arrows indicate colocalization. $\boldsymbol{E}$, Quantification of cFos and NeuN double-labeled neurons in the IL $\left(n=14\right.$ /reward). Results are expressed as the fraction of double-labeled neurons. Data mean \pm SEM. ${ }^{*} p<0.05$. For detailed statistics, see Table 2 .

cant differences at the inactive lever between the ethanol and saccharin conditions, but this effect was inconsistent (Fig. 1C; Table 1) and did not reoccur in the other experiments (Figs. $2 B, C, 3 B)$. Still, animals pressed the active lever far more often than the inactive one, independent of the reward presented (Fig. $1 B, C$; Table 1), showing that they had learned the behavioral contingencies. In summary, we have established an experimental paradigm that allows us to investigate the neurobiological mechanisms underlying alcohol and natural reward-seeking behavior within the same animal.

Saccharin and ethanol seeking are encoded in the IL by neuronal ensembles of similar size

Although neuronal ensembles involved in seeking for various rewards have been identified in several studies (Dayas et al., 2007;
Koya et al., 2009; Bossert et al., 2011; Cruz et al., 2014; Pfarr et al., 2015; Suto et al., 2016; Warren et al., 2016), differences in the behavioral protocols or batch and strain differences make a comparison of these studies difficult. To overcome such limitations and to directly compare natural and drug reward seeking, we used a two-reward operant conditioning procedure for ethanol and saccharin with matched behavioral performance followed by extinction, and upon reinstatement for either reward, detection of the $\mathrm{cFos}$ response in the IL. A cohort of $32 \mathrm{Wistar}$ rats was trained on the two-reward operant paradigm. The behavioral performance for self-administration, extinction, and cue-induced reinstatement in two counterbalanced sessions for the EtOH and saccharin conditions is shown in Figure $1 B$. Four rats were excluded because they failed to reach the criterion for successful reinstatement ( $>15$ lever presses in $30 \mathrm{~min}$ ). Full statistics are 

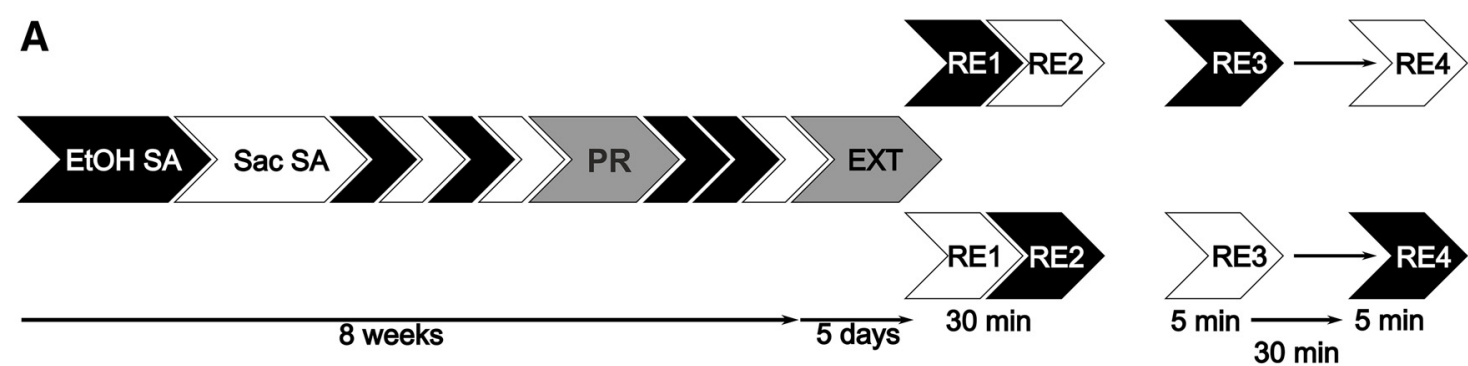

8 weeks

C

D
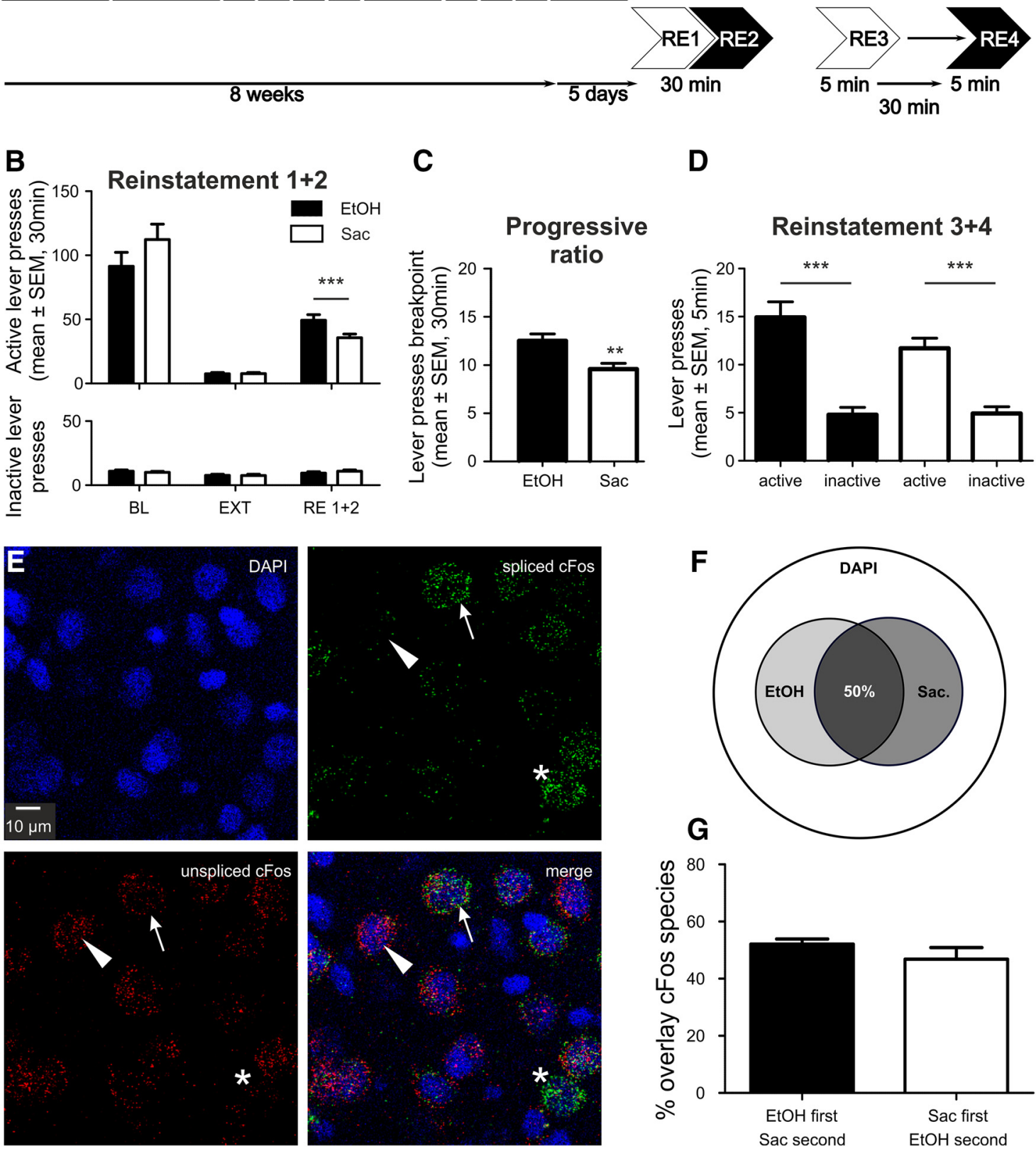

Figure 3. Largely overlapping IL ensembles involved in ethanol and saccharin seeking. $A$, Experimental timeline for ethanol (EtOH) and saccharin (Sac) self-administration (SA), extinction (EXT), and counterbalanced cued reinstatement sessions (RE1 +2 ) and a final session (RE3 $+4, n=14$ ) for activation of ethanol and saccharin ensembles in the same animal. $\boldsymbol{B}$, Active and inactive lever presses (mean \pm SEM) for ethanol and saccharin self-administration baseline (BL), EXT and RE1 $+2(n=24)$. C, Breakpoint analysis (PR) for the ethanol and saccharin rewards $(n=24)$. $\boldsymbol{D}$, Lever presses (mean \pm SEM) for EtOH and saccharin in RE3 $+4(n=14)$. $E$, Representative images of double $c F$ Os ISH for DAPI counterstaining, spliced and unspliced $c$ Fos. Arrows indicate a double-positive cell. Triangles represent a single-positive cell for unspliced CFos. Asterisks indicate single-positive cell for spliced cFos only. $\boldsymbol{F}$, Venn diagram indicating the size of saccharin and ethanol ensembles in relation to total cell number (DAPI). G, Quantification of overlay between both ensembles (mean \pm SEM). ${ }^{* *} p<0.01,{ }^{* * *} p<0.001$. For detailed statistics, see Results and Table 3.

listed in Table 2. Notably, despite matched self-administration performance for both rewards, we found a small but significant increase in the reinstatement response for ethanol compared with saccharin. Before the final reinstatement test, animals were ranked based on their previous reinstatement performance and equally split into two groups. Five days after injections of retrograde tracers (see below), the rats successfully underwent the final cue-induced rein- statement for either EtOH or saccharin seeking ( $n=14 /$ reward; Fig. 2C; Table 2). After the session, rats were killed and the number of IL neurons activated during the final reinstatement session was assessed by double-labeling immunohistochemistry for NeuN (neuronal marker) and cFos. We found no difference in the fraction of cFos-expressing neurons induced by either saccharin or EtOH seeking (saccharin: $15.32 \pm 0.63 \%$, ethanol: $14.9 \pm 0.58 \%$, 
Table 2. Statistics of Experiment 1: results for repeated-measures ANOVA and Newman-Keuls post hoc test ${ }^{a}$

\begin{tabular}{|c|c|c|c|c|c|c|c|c|c|c|c|c|}
\hline \multirow[b]{3}{*}{ Lever } & \multirow{2}{*}{\multicolumn{5}{|c|}{ Repeated-measures ANOVA }} & \multicolumn{5}{|c|}{ Newman-Keuls post hoc test } & & \\
\hline & & & & & & \multicolumn{3}{|c|}{ Within-group comparison } & \multicolumn{2}{|c|}{$\begin{array}{l}\text { Between-group } \\
\text { comparison }\end{array}$} & \multicolumn{2}{|c|}{$\begin{array}{l}t \text { test (comparison } \\
\text { active/inactive) }\end{array}$} \\
\hline & Test & df & Effect & $F$ & $p$ & Reward & Test & $p$ & Test & $p$ & Test & $p$ \\
\hline \multirow[t]{4}{*}{ Active RE $1+2$} & BL, EXT & 1,54 & reward & 0.01 & 0.917 & & & & & & $\mathrm{EtOH}$ & \\
\hline & & & Test-session & 107.94 & 0.0001 & $\mathrm{EtOH}$ & BL, EXT & 0.0001 & BL & 0.89 & $\mathrm{BL}$ & 0.0001 \\
\hline & & & Interaction & 0.008 & 0.928 & $\mathrm{Sac}$ & BL, EXT & 0.0001 & EXT & 0.99 & EXT & 0.889 \\
\hline & & & interaction & 3.246 & 0.077 & $\mathrm{Sac}$ & EXT, RE1 + 2 & 0.0001 & RE1 +2 & 0.01 & & \\
\hline \multirow[t]{5}{*}{ Inactive RE $1+2$} & BL, EXT & 1,54 & reward & 0.098 & 0.755 & & & & & & Saccharin & \\
\hline & & & Test-session & 159.09 & 0.0001 & $\mathrm{EtOH}$ & BL, EXT & 0.0002 & $B L$ & 0.54 & $\mathrm{BL}$ & 0.0001 \\
\hline & & & interaction & 0.422 & 0.518 & $\mathrm{Sac}$ & BL, EXT & 0.0001 & EXT & 0.93 & EXT & 0.889 \\
\hline & EXT, RE1 + 2 & 1,54 & reward & 0.029 & 0.865 & & & & & & & \\
\hline & & & Test-session & 41.168 & 0.0001 & $\mathrm{EtOH}$ & EXT, RE1 + 2 & 0.0002 & & & RE1 + 2 & 0.0001 \\
\hline \multirow{3}{*}{ Active RE 3} & EXT, RE3 & 1,26 & reward & 9.576 & 0.005 & & & & & & & \\
\hline & & & Test-session & 315.38 & 0.0001 & $\mathrm{EtOH}$ & EXT, RE3 & 0.0001 & & & RE3 & 0.0001 \\
\hline & & & interaction & 13.967 & 0.0009 & $\mathrm{Sac}$ & EXT, RE3 & 0.0001 & RE3 & 0.0001 & & \\
\hline \multirow[t]{6}{*}{ Inactive RE 3} & BL, EXT & 1,26 & reward & 2.367 & 0.136 & & & & & & Saccharin & \\
\hline & & & Test-session & 107.27 & 0.0001 & $\mathrm{EtOH}$ & BL, EXT & 0.0001 & $\mathrm{BL}$ & 0.02 & $\mathrm{BL}$ & 0.0026 \\
\hline & & & interaction & 3.275 & 0.082 & $\mathrm{Sac}$ & BL, EXT & 0.0001 & EXT & 0.91 & EXT & 0.586 \\
\hline & EXT, RE3 & 1,26 & reward & 1.16 & 0.291 & & & & & & & \\
\hline & & & Test-session & 37.699 & 0.0001 & $\mathrm{EtOH}$ & EXT, RE3 & 0.0002 & & & RE3 & 0.0003 \\
\hline & & & interaction & 1.101 & 0.304 & $\mathrm{Sac}$ & EXT, RE3 & 0.004 & RE3 & 0.14 & & \\
\hline
\end{tabular}

${ }^{a}$ Comparison between active and inactive lever was done using two-tailed paired $t$ test. BL, Self-administration baseline; EXT, extinction; RE, cue-induced reinstatement; EtOH, ethanol; Sac, saccharin.

Table 3. Statistics of Experiment 2: results for repeated-measures ANOVA and Newman-Keuls post hoc test ${ }^{a}$

\begin{tabular}{|c|c|c|c|c|c|c|c|c|c|c|c|c|}
\hline \multirow[b]{3}{*}{ Lever } & \multirow{2}{*}{\multicolumn{5}{|c|}{ Repeated-measures ANOVA }} & \multicolumn{5}{|c|}{ Newman-Keuls post hoc test } & & \\
\hline & & & & & & \multicolumn{3}{|c|}{ Within-group comparison } & \multicolumn{2}{|c|}{$\begin{array}{l}\text { Between-group } \\
\text { comparison }\end{array}$} & \multicolumn{2}{|c|}{$\begin{array}{l}t \text { test (comparison } \\
\text { active/inactive) }\end{array}$} \\
\hline & Test & $\mathrm{df}$ & Effect & $F$ & $p$ & Reward & Test & $p$ & Test & $p$ & Test & $p$ \\
\hline \multirow[t]{6}{*}{ Active } & BL, EXT & 1,46 & reward & 1.547 & 0.219 & & & & & & $\mathrm{EtOH}$ & \\
\hline & & & Test-session & 146.81 & 0.0001 & $\mathrm{EtOH}$ & BL, EXT & 0.0001 & $\mathrm{BL}$ & 0.07 & $B L$ & 0.0001 \\
\hline & & & interaction & 1.771 & 0.189 & $\mathrm{Sac}$ & BL, EXT & 0.0001 & EXT & 0.99 & EXT & 0.949 \\
\hline & EXT, RE $1+2$ & 1,46 & reward & 5.551 & 0.023 & & & & & & & \\
\hline & & & Test-session & 176.80 & 0.0001 & $\mathrm{EtOH}$ & EXT, RE1 + 2 & 0.0002 & & & $\mathrm{RE} 1+2$ & 0.0001 \\
\hline & & & interaction & 6.788 & 0.012 & $\mathrm{Sac}$ & EXT, RE1 + 2 & 0.0001 & $\mathrm{RE}$ & 0.0009 & & \\
\hline \multirow[t]{6}{*}{ Inactive } & BL, EXT & 1,46 & reward & 0.219 & 0.642 & & & & & & Saccharin & \\
\hline & & & Test-session & 16.127 & 0.0002 & $\mathrm{EtOH}$ & BL, EXT & 0.006 & $\mathrm{BL}$ & 0.48 & $\mathrm{BL}$ & 0.0001 \\
\hline & & & interaction & 0.336 & 0.565 & $\mathrm{Sac}$ & BL, EXT & 0.049 & EXT & 0.95 & EXT & 0.949 \\
\hline & EXT, RE $1+2$ & 1,46 & reward & 0.394 & 0.533 & & & & & & & \\
\hline & & & Test-session & 7.285 & 0.009 & $\mathrm{EtOH}$ & EXT, RE1 + 2 & 0.195 & & & $\mathrm{RE} 1+2$ & 0.0001 \\
\hline & & & interaction & 0.707 & 0.405 & Sac & EXT, RE1 + 2 & 0.073 & $\mathrm{RE}$ & 0.31 & & \\
\hline
\end{tabular}

${ }^{a}$ Comparison between active and inactive lever was done using two-tailed paired $t$ test. BL, Self-administration baseline; EXT, extinction; RE, cue-induced reinstatement; EtOH, ethanol; Sac, saccharin.

$t_{(1,26)}=0.49, p=0.63, n=14 /$ reward, two-tailed, unpaired $t$ test; Fig. $2 D, E)$. Thus, the IL neuronal ensembles reacting to either a drug or a natural reward cue are similar in size.

The neuronal ensembles of saccharin and ethanol seeking in the IL are largely overlapping

Despite showing the number and localization of activated neurons, the previous experiment could not determine whether the ethanol and saccharin ensembles are comprised of shared or distinct populations of neurons. This question can only be answered by assessing the cFos response associated with the respective behavior within the same animal. Toward this aim, we trained 24 rats on the two-reward operant paradigm. Behavioral perfor- mance for self-administration, extinction, and cue-induced reinstatement in two counterbalanced sessions for the EtOH and saccharin conditions was similar to the first experiment (Fig. 3B; for full statistics, see Table 3). The specific motivation of the animals for each reward was assessed in two PR tests performed during self-administration training. We observed a significantly higher break point for the EtOH compared with the saccharin reward $\left(t_{(1,46)}=3.122, p=0.0031\right.$, two-tailed, paired $t$ tests; Fig. $3 C)$ as well as significantly more lever presses for the ethanol reward $(55.71 \pm 5.29)$ compared with saccharin (35.04 \pm 3.32$)$ $\left(t_{(1,46)}=3.312, p=0.0018\right.$, paired $t$ test; data not shown $)$. Rats also responded significantly more for the ethanol condition in the reinstatement tests (Fig. 3B). Thus, despite matched self-admini- 
stration performance, ethanol seems more rewarding than the diluted saccharin solution under the present conditions.

To elicit two distinct neuronal responses (one associated with ethanol and one with saccharin seeking), rats were subjected to a final session comprised of two brief 5 min reinstatement tests, 30 min apart, and counterbalanced for the two sets of cues. Fourteen rats reinstated successfully for both rewards under these conditions (Fig. 3D). No differences in first versus second reinstatement for each reward were found $\left(\mathrm{EtOH}: t_{(1,12)}=0.73, p=0.46\right.$; saccharin: $t_{(1,12)}=0.07, p=0.95$, two-tailed, unpaired $t$ test); thus, responses for each reward were pooled for the analysis. In summary, the data show that rats are able to discriminate between the two reward contingencies even under the brief access conditions.

To distinguish two sets of $c \mathrm{Fos}^{+}$neurons triggered by stimuli $30 \mathrm{~min}$ apart, we used a double-FISH method that is based on the different temporal profiles of nascent (unspliced) and mature (spliced) cFos mRNA species. Upon a stimulus, cFos mRNA is rapidly transcribed within a few minutes, but this nascent form has a rapid turnover and is quickly undergoing splicing (Jurado et al., 2007). Lin et al. (2011) demonstrated that the intron containing $c$ Fos mRNA can be detected in the brain within 5 min after a behavior task, whereas solely mature $c$ Fos mRNA can be detected $30 \mathrm{~min}$ after. This time course was adopted here. The advantage of detecting two $c$ Fos isoforms is that both $c$ Fos RNA species are subject to the same underlying induction kinetics, which is not the case with other immediate early genes (e.g., arc and homer la) (Bottai et al., 2002; Vazdarjanova et al., 2002). Thus, neurons active during the first reinstatement are labeled by mature $c$ Fos mRNA, whereas those activated by the second reinstatement are marked by nascent $c$ Fos mRNA (Fig. $3 E$ ). We found no significant differences in the proportion of mature $c F o s$ mRNA-expressing cells reflecting the first $\mathrm{EtOH}$ or saccharin reinstatement $(25 \pm$ $1 \%$ vs $23 \pm 2 \%$, respectively, $t_{(1,12)}=0.715, p=0.488$, two-tailed, unpaired $t$ test). The proportion of $c \mathrm{Fos}^{+}$cells is higher compared with the first experiment $(\sim 15 \%)$, which is to be expected given the higher sensitivity of FISH compared with immunohistochemical detection (Laiho et al., 2016). There was also no difference in the nascent $c$ Fos populations $\left(t_{(1,12)}=0.63, p=0.54\right)$. Colocalization analysis revealed $\sim 50 \%$ overlap between mature and nascent $\mathrm{cFos}^{+}$cells regardless of the order of the two successive cued reinstatement tests $\left(t_{(1,12)}=1.190, p=0.257\right.$; Fig. $3 F, G)$. Next, we determined whether the observed mature and nascent $\mathrm{CFos}^{+}$cells belonged to the same ensemble or whether they constitute separate, reward-specific ensembles. Therefore, we used bootstrap analysis, which allows the detection of ensembles in environments that are intrinsically noisy, due to background activity (e.g., Hamm et al., 2017). Bootstrap analysis confirmed that the distribution of cells expressing either one, both, or none of the cFos transcripts obtained experimentally is significantly different from a randomly sampled population, and that the order in which the cues were presented did not influence the results (Fig. 4). The bootstrap analysis further allows us to conclude that the two reinstatement cues activate distinct ensembles that are overlapping. If both cues would recruit the same ensemble and the distributions of single and double-positive cells found in our experiments would be subpopulations of this single ensemble that have been observed by chance (e.g., due to factors introduced by our experimental design or the detection method), the observed number of double-positive cells should lie right within the random distribution generated by the bootstrap analysis. Because this is clearly not the case (Fig. 4, black line and distribution), we are confident that reinstatement with two different cues actually recruits two distinct but overlapping ensembles.
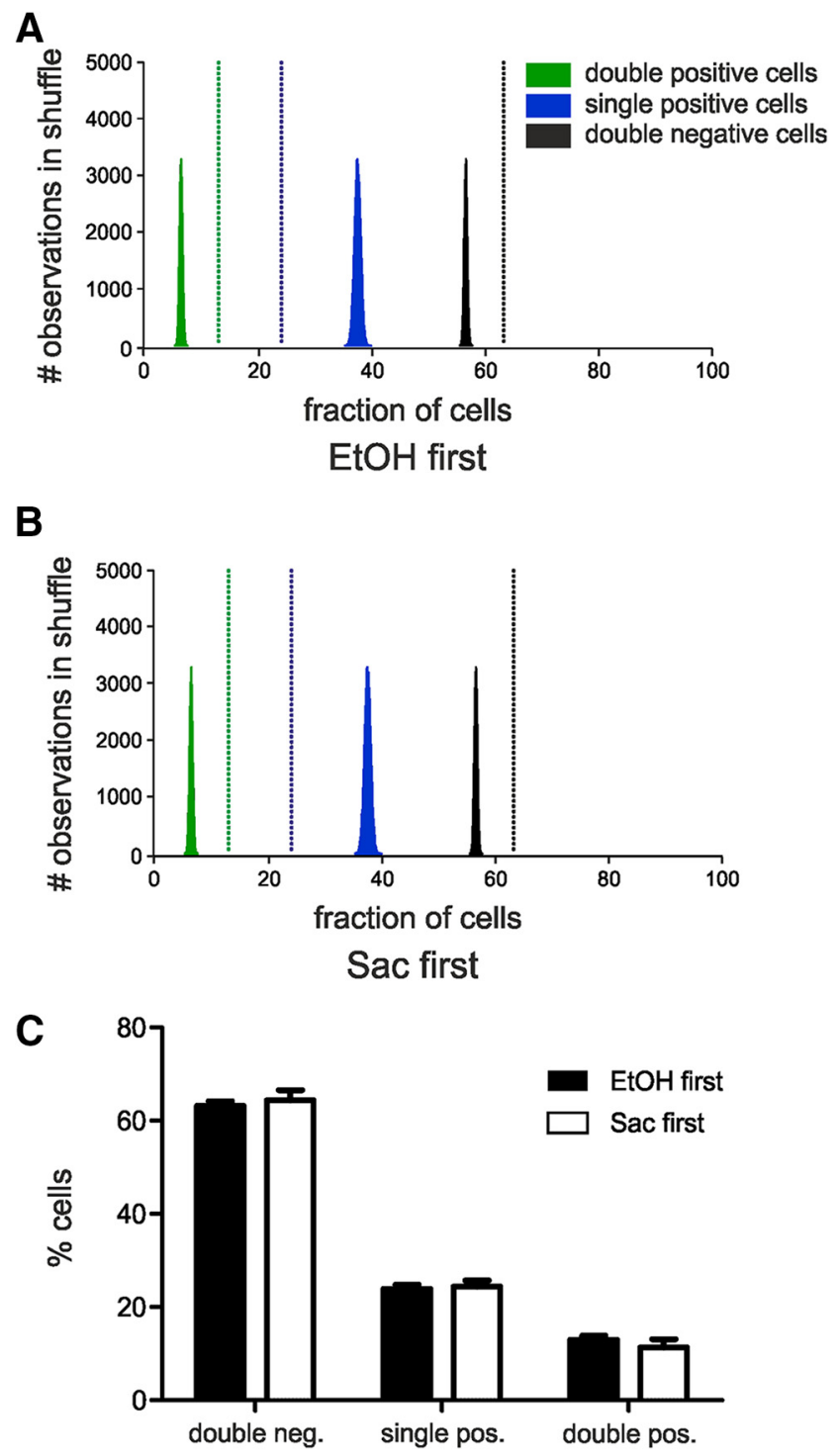

Figure 4. Bootstrap analysis confirms that neuronal IL ensembles activated by cue-induced reinstatement of ethanol (EtOH) and saccharin ( $\mathrm{Sac}$ ) seeking, detected by FISH against different cFos mRNA species are highly nonrandom, independent of the order of cues presented for reinstatement. $\boldsymbol{A}, \boldsymbol{B}$, Histograms of random distributions of cells expressing one, both, or none of the cFos mRNA obtained by 100,000 shuffles. Vertical and dashed lines indicate the fractions of cells experimentally determined. C, Quantification of cells expressing one, both, or none of the cFos mRNA species, according to the reward reinstated first.

Together, the brief two-reward operant protocol in combination with double-cFos FISH analysis is suitable for the detection of distinct, neuronal ensembles within the same animal. Within the IL, the neuronal ensembles involved in reward-seeking behavior for ethanol and saccharin are distinct but overlapping, each consisting of a subpopulation of cells that are broadly activated by both reward-paired cues and a fraction of cells that is specific for each reward.

\section{Further characterization of the neuronal ensembles involved} in saccharin and ethanol seeking

We reported previously that the $\mathrm{cFos}^{+}$cells found after cued reinstatement of ethanol seeking are nearly exclusively neurons, of which the majority belongs to the glutamatergic class (Pfarr et al., 2015). Here, we were interested in the functional organization of the glutamatergic neurons comprising the similar ethanol and 

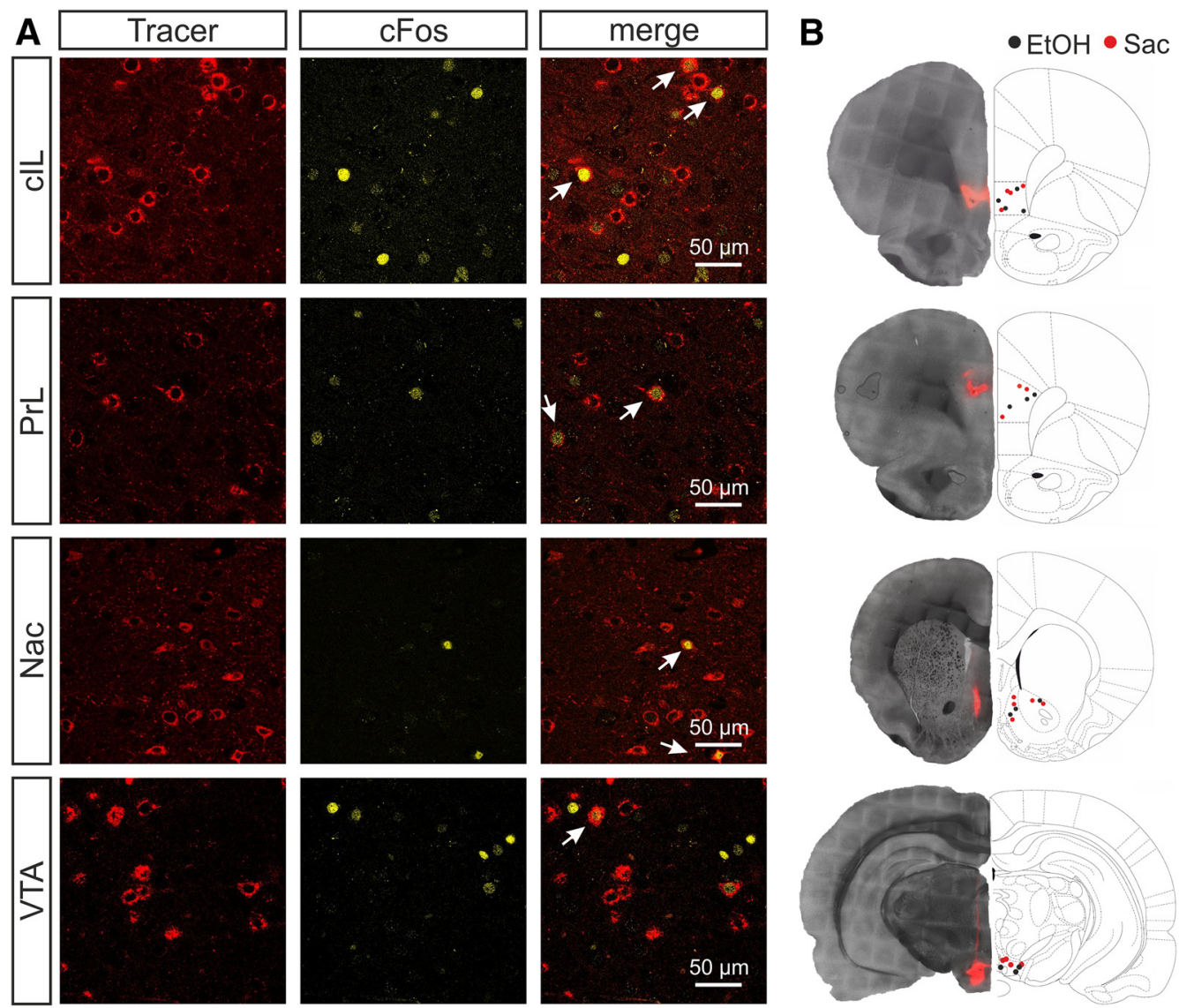

C
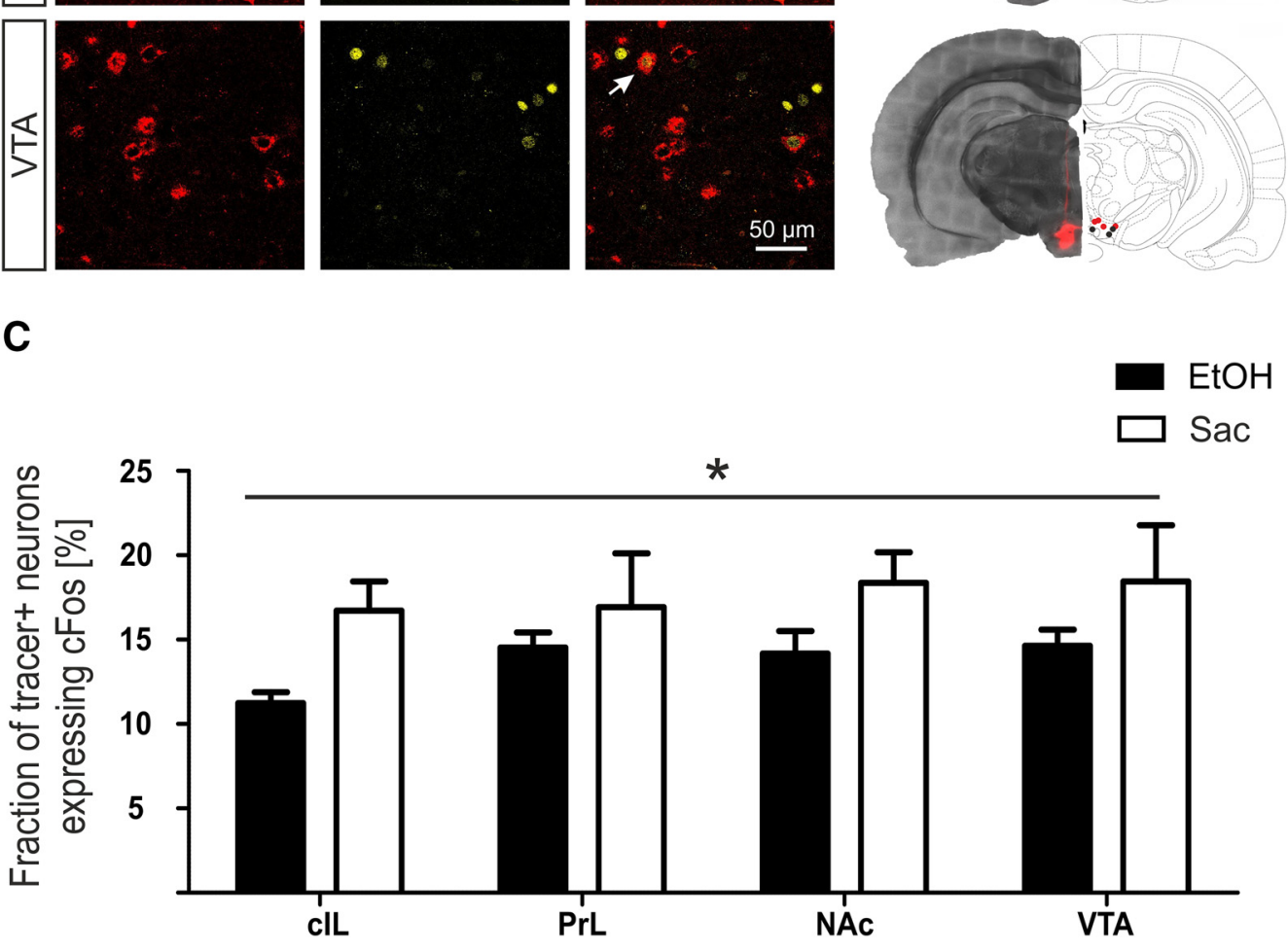

Figure 5. Differences in activated IL projections during ethanol and saccharin seeking behavior. $A$, Representative images of retrograde tracer signals and cFos immunolabeling in the IL. Top to bottom, Colocalization of cFos with retrograde tracer signals from contralateral IL (clL), ipsilateral prelimbic cortex (PrL), nucleus accumbens (NAc) and ventral tegmental area (VTA). Arrows indicate colocalization. B, Black dots represent injection placements for ethanol (EtOH). Red circles represent injection placements for the saccharin (Sac) group. Injection sites were verified in contralateral IL and PrL $3.0 \mathrm{~mm}$ anterior to bregma, Nac $1.6 \mathrm{~mm}$ anterior to bregma, and VTA -5.3 posterior to bregma. Adapted from Paxinos and Watson (1998). C, Quantification of the fraction of $\mathrm{CFos}{ }^{+}$tracer neurons (mean \pm SEM) of activated IL projections during ethanol and saccharin seeking. ${ }^{*} p<0.05$.

saccharin ensembles. First, we asked whether the two $\mathrm{cFos}^{+}$neuronal populations segregate in their anatomical projection targets. Rats that had received injections of the retrograde tracer cholera toxin B into relevant target areas (Fig. 2A) were assessed for ipsilateral (NAc, VTA, PrL) or contralateral (IL) colabeling of the tracer with cFos immunoreactivity (Fig. $5 A, C$ ). Given the extensive connectivity of the IL with $>60$ outgoing projection (Hurley et al., 1991; Vertes, 2004; Noori et al., 2017), our finding suggests the existence of a wide network of axon collaterals, at least between the four selected projection targets. Also notable, we found significantly more colabeling of IL neurons activated by the saccharin cue compared with EtOH consistently for all targets (two-way ANOVA for reward $\times$ target: reward effect $F_{(1,27)}=$ $6.69, p=0.018$; region effect $F_{(1,27)}=0.57, p=0.64$; interaction $F_{(1,27)}=0.16, p=0.92$; Fig. $\left.5 C\right)$. Given that the overall number of neurons activated by the EtOH or saccharin cues was not differ- 

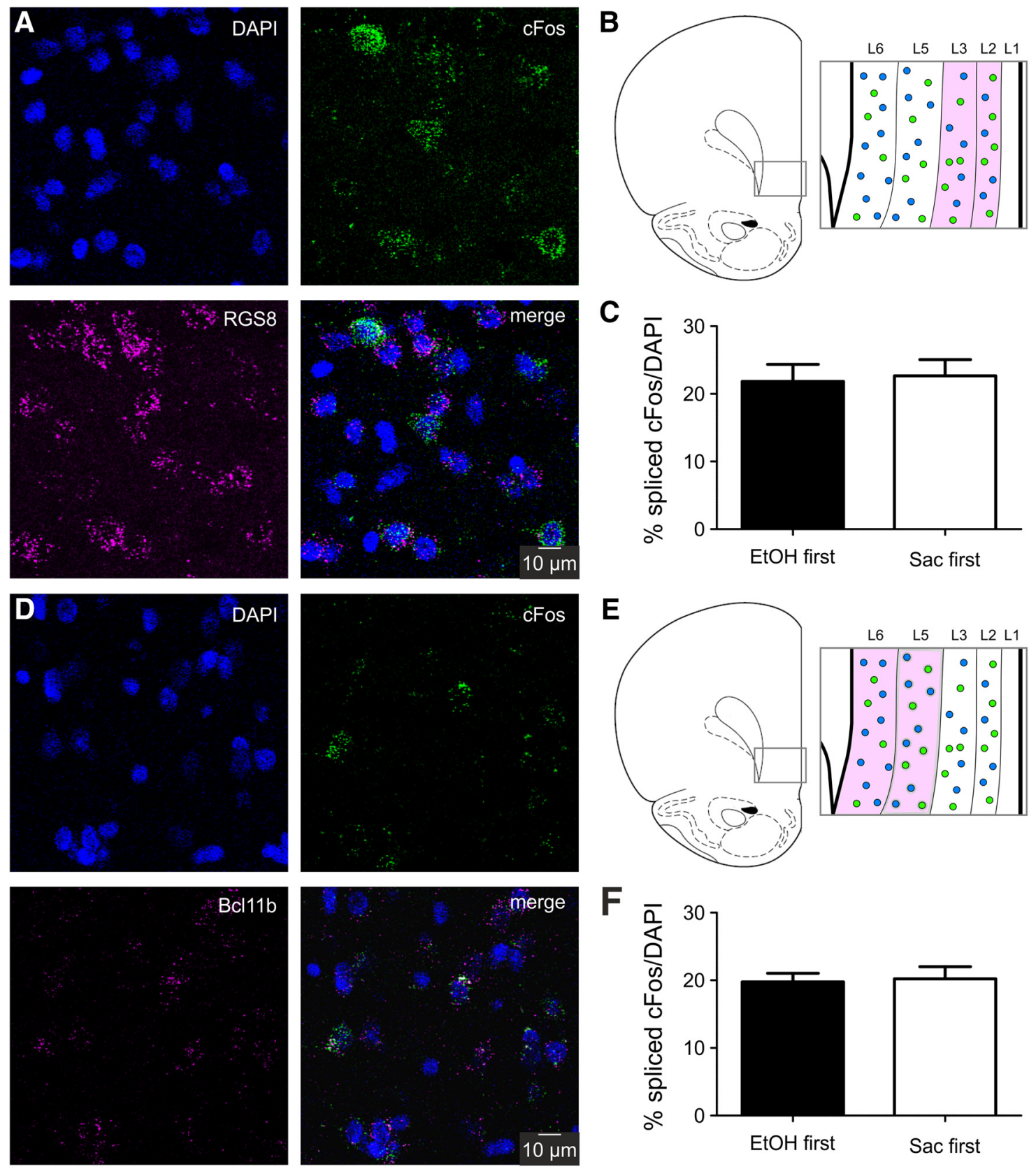

Figure 6. Laminar distribution of cFos mRNA expression. $A$, Representative images of FISH for spliced (Fos mRNA (green), layer 2/3 marker RGS8 (magenta), and DAPI (blue). Expression of the layer marker was used to confirm image acquisition within the correct layer of the IL. B, Schematic of laminar structure of the IL. Magenta represents the analyzed region (layer $2 / 3$ ). C, Quantification of the ratio of spliced (Fos-expressing cells in layer $2 / 3$ of the IL after cue-induced reinstatement of ethanol ( $\mathrm{EtOH}, n=7$ ) or saccharin (Sac, $n=7)$ seeking. D, Representative images of FISH for spliced cFos mRNA (green), the layer 5/6 marker Bd11b (magenta), and DAPI (blue). $E$, Schematic of laminar structure of the IL. Magenta represents the analyzed region (layer $5 / 6) . F$, Quantification of the ratio of spliced cFos-expressing cells in layer $5 / 6$ of the IL after cue-induced reinstatement of ethanol (EtOH, $n=7$ ) or saccharin $(\mathrm{Sac}, n=7)$ seeking.

ent (Fig. 2E), this finding suggests that ethanol seeking may engage a wider network of IL projections from areas not examined in this study, or that a single neuron activated by saccharin cues projects into several of the examined target areas.

Previous research found that both superficial and deep pyramidal neurons of the IL are projecting to distinct cortical and subcortical targets (Gabbott et al., 2005). Therefore, we examined the layer distribution of the neurons activated by either the ethanol or the saccharin cues. The laminar structure of the mPFC differs from that of most other cortical regions inasmuch it lacks a layer IV, and thus clear definition of input and output layers (Uylings et al., 2003; Riga et al., 2014). We used double-labeling
FISH of mature $c$ Fos mRNA with the layer-specific expression of Bcl11b (layer 5/6) and RGS8 (layer 2/3) mRNA (Molyneaux et al., 2007). No differences in layer distribution of the $\mathrm{EtOH}$ and saccharin cue-activated neurons were found (Fig. 6), further demonstrating the similar organization of the two ensembles.

\section{Discussion}

The data presented here provide novel insight into the organization of memory processing within the infralimbic cortex, a subregion of the $\mathrm{mPFC}$ with highly integrative function supporting decision making. Our key finding is that two discrete contextual memories on the availability of alcohol or a natural reward are 
processed by largely overlapping neuronal ensembles of similar size and composition. Identification of the two $\mathrm{CFos}^{+}$neuronal ensembles within the same animal was possible using a novel operant protocol for concurrent self-administration of two rewards in combination with double-FISH for separate detection of nascent and mature $c$ Fos transcripts.

\section{The dual-reward behavioral procedure}

The behavioral procedure used here is a modification of a training protocol for the conditioned self-administration, extinction, and reinstatement of responding to alcohol that is widely applied as a model of relapse in alcohol use disorder (Spanagel, 2000; Crombag and Shaham, 2002; Epstein et al., 2006; Sanchis-Segura and Spanagel, 2006; Martin-Fardon and Weiss, 2013; Marchant et al., 2015). Alcohol is a weak reinforcer compared with saccharin in rodents. Indeed, rats will nearly always choose saccharin over most drugs of abuse in choice paradigms (Lenoir et al., 2007; Madsen and Ahmed, 2015). Taking into account this in combination with the much higher response rates for a standard $0.2 \%$ saccharin solution during operant self-administration, we used a saccharin solution that was diluted to match the behavioral performance obtained with alcohol. The availability of both rewards was predicted by a discriminant odor and a responsecontingent light cue. Although the two sets of cues are similar, the rats were able to discriminate between the contingencies for alcohol and saccharin as demonstrated by breakpoint and reinstatement tests. Despite similar self-administration rates for both rewards, rats show higher motivation for seeking of alcohol. The response bias for alcohol is seen consistently across all experiments (Figs. 1, 2, and 3), and would not be expected if rats simply generalize lever pressing behavior. In summary, the present behavioral paradigm provides a robust protocol for investigating the neural mechanisms underlying alcohol and natural rewardseeking within the same animal.

\section{Detection of reward-associated IL ensembles}

The functional ensemble that is activated within the IL was defined by spatiotemporal coordinated cFos expression upon recall of reward memories. For alcohol seeking as the only reward option, we previously demonstrated that the population of cells showing cFos induction comprises $\sim 11 \%$ of IL neurons, most of which belonging to the glutamatergic class, $<10 \%$ were GABAergic neurons with no detectable participation of glial cells (Pfarr et al., 2015). Here, we used two distinct methods to detect $\mathrm{cFos}^{+}$ neurons: immunostaining and mRNA FISH. The ensemble size estimated by our cFos immunostaining approach was somewhat larger as in our previous study (11\% vs 15\%) (Pfarr et al., 2015), and comprises distinctly more IL neurons than reported after similar experiments with cocaine or heroin (Koya et al., 2009; Bossert et al., 2011; Cruz et al., 2014) as well as with natural rewards (Suto et al., 2016; Warren et al., 2016). The ensembles reported in these studies comprise $\sim 3 \%-6 \%$ of neurons within the brain region. It can be speculated that the complex and largely similar contingencies (e.g., contextual and visual cues, positive valence and shared properties of the rewards, etc.) engage a wider network compared with experiments with highly distinct predictive cues and could thus contribute to the overlap of both ensembles. Also, a general motivation to obtain a reward may be represented in the ensemble overlap. However, the specific rewards are highly different in nature, both in their sensory perception (taste, smell) and the internal states they produce, and therefore perceived as different by the animal. This is supported by the consistent differences in responding under PR and reinstatement conditions. Such reward- specific properties may be encoded by the nonoverlapping parts of the respective $\mathrm{cFos}^{+}$ensembles.

Furthermore, our results are supported by a study demonstrating that exploration of two different environmental contexts induced similar large and intersecting populations of $\mathrm{cFos}^{+}$neurons as observed here (Cai et al., 2016). Using ISH, the population of $\mathrm{cFos}^{+}$neurons in our experiment was even larger, emphasizing the impact of methodological factors, such as sensitivity on the size of a distinct detected ensemble and, therefore, the advantage of the present within-subject double-cFos FISH approach.

\section{cFos expression and behavioral output}

Notably, neither the number of $c \mathrm{Fos}^{+}$neurons in the IL nor the intensity of their cFos expression was correlated with the behavioral performance (i.e., the number of operant responses) (data not shown). This is not surprising given the pleiotropic regulation and function of this gene. For one thing, cFos is involved in maintaining basal, nonstimulated activity of neurons as demonstrated by local acute antisense interference in the brain of adult rats (Sommer et al., 1996; Strömberg et al., 2004). Otherwise and relevant in the present context, stimulus-induced gene expression of cFos provides an important mechanism of synapse-to-nucleus communication. This process is rapid (increased expression can be detected within a few minutes) and linear correlated to the amount of firing from the neurons (Chawla et al., 1998; Dai et al., 2009). However, the study by Chawla et al. (1998) also showed that the signals for shaping the kinetics of cFos expression are not only related to electrical activity of neurons. Specifically, BDNF, a neurotrophic factor with a recently demonstrated role within corticostriatal circuits in controlling alcohol consumption (Darcq et al., 2015; Heilig et al., 2017), seems to regulate cFos in a nonlinear all-on/off fashion. Thus, cFos represents a class of highly dynamically and complex regulated coincidence detectors that integrate various external and internal signals.

Nevertheless, the functional importance of the cFos expression for behavioral output has been established. Specific chemogenetic ablation of $\mathrm{cFos}^{+}$IL neurons, which were activated by the same set of alcohol-predicting cues as used here, resulted in excessive seeking responses (Pfarr et al., 2015). The action of this IL ensemble was distinct from activated cells in the neighboring prelimbic region, but also from IL cells activated by stress induced reinstatement of alcohol seeking, demonstrating some specificity for the distinct contingencies encoded by these neurons. Several studies have identified functional neuronal ensembles within the rat mPFC critically involved in drug and reward seeking behavior (Bossert et al., 2011; Cruz et al., 2015; Pfarr et al., 2015; Suto et al., 2016; Warren et al., 2016), whereby the functional output of these IL ensembles was inconsistent (i.e., either initiation or suppression of reward seeking was found), indicating that one or more cue- or reward-related functional ensembles coexist in the mPFC (Schwindel and McNaughton, 2011). Furthermore, in vivo multiarray recording experiments demonstrated that neurons in the $\mathrm{mPFC}$, including the IL, can signal contextual information that promotes reward seeking in response to discriminative stimuli, regardless of whether this involves initiation or suppression of neural activity (Moorman and Aston-Jones, 2015).

\section{Role of the IL in response selection}

How to explain these apparently conflicting results? The mPFC is among the most highly connected regions of the rat brain (Noori et al., 2017). Specifically, the IL has $>60$ established projection areas and receives projections from $\sim 40$ regions. Such a high connectivity hub is expected to need large capacity for informa- 
tion processing, which may also be reflected in the size of the $\mathrm{cFos}^{+}$ensembles and the extent of their shared neuronal populations. Together, these observations make it unlikely that a distinct memory trace, such as the properties of a given reward, is represented in the IL. Hence, our data do not support a distinct control function for governing conditioned appetitive and aversive behaviors as proposed in a PrL-Go/IL-NoGo model (Peters et al., 2009). A more complex model of functional compartmentalization of the mPFC proposes that the prelimbic subdivision is mainly involved in the learning of rules, whereas the IL supports flexibility of this response and the ability to shift toward new strategies when contingencies change (Heidbreder and Groenewegen, 2003; Seamans et al., 2008). Thus, the different outcomes in IL lesion experiments reported in the literature may be better explained by a role of this region in the momentary assessment of information passing through, as a brief state. Thereafter, responses may be executed or withheld for which the subject has already been procedurally, contextually, and emotionally conditioned. In humans, meditation training aims to access and extend such metacognitive/ metaemotional states of self-awareness for reducing cue-induced drug craving and to relief stress and pain. Interestingly, neuroimaging studies of such mindfulness-based therapies repeatedly found distinct activation of the subgenual cingulate cortex, the human homolog of the IL (Tang et al., 2009; Tang and Tang, 2013; Westbrook et al., 2013; Zeidan et al., 2015).

Together, we provide a novel experimental framework for the study of neuronal ensembles involved in reward seeking. By combining a two-reward operant conditioning task with double-cFos FISH detection, we were able to directly compare the cellular response to two distinct reward seeking events. Thereby, we demonstrated that seeking for natural and drug rewards is encoded in the IL by distinct but largely overlapping ensembles, a finding that is in agreement with the integrator function of the mPFC. When preferences for two rewards is fairly matched, the respective information is apparently processed by highly similarly organized ensembles in the IL. Whether this changes under conditions of strong response biases, such as in addictive disorders, should be addressed in further studies.

\section{References}

American Psychiatric Association (2013) Diagnostic and statistical manual of mental disorders, Ed 5. Washington, DC: American Psychiatric Association.

Bossert JM, Stern AL, Theberge FR, Cifani C, Koya E, Hope BT, Shaham Y (2011) Ventral medial prefrontal cortex neuronal ensembles mediate context-induced relapse to heroin. Nat Neurosci 14:420-422. CrossRef Medline

Bottai D, Guzowski JF, Schwarz MK, Kang SH, Xiao B, Lanahan A, Worley PF, Seeburg PH (2002) Synaptic activity-induced conversion of intronic to exonic sequence in homer 1 immediate early gene expression. J Neurosci 22:167-175. Medline

Cai DJ, Aharoni D, Shuman T, Shobe J, Biane J, Song W, Wei B, Veshkini M, La-Vu M, Lou J, Flores SE, Kim I, Sano Y, Zhou M, Baumgaertel K, Lavi A, Kamata M, Tuszynski M, Mayford M, Golshani P, et al (2016) A shared neural ensemble links distinct contextual memories encoded close in time. Nature 534:115-118. CrossRef Medline

Chawla S, Hardingham GE, Quinn DR, Bading H (1998) CBP: a signalregulated transcriptional coactivator controlled by nuclear calcium and CaM kinase IV. Science 281:1505-1509. CrossRef Medline

Ciccocioppo R, Martin-Fardon R, Weiss F (2002) Effect of selective blockade of $\mathrm{mu}(1)$ or delta opioid receptors on reinstatement of alcohol-seeking behavior by drug-associated stimuli in rats. Neuropsychopharmacology 27:391-399. CrossRef Medline

Ciccocioppo R, Lin D, Martin-Fardon R, Weiss F (2003) Reinstatement of ethanol-seeking behavior by drug cues following single versus multiple ethanol intoxication in the rat: effects of naltrexone. Psychopharmacology (Berl) 168:208-215. CrossRef Medline
Crombag HS, Shaham Y (2002) Renewal of drug seeking by contextual cues after prolonged extinction in rats. Behav Neurosci 116:169-173. CrossRef Medline

Cruz FC, Koya E, Guez-Barber DH, Bossert JM, Lupica CR, Shaham Y, Hope BT (2013) New technologies for examining the role of neuronal ensembles in drug addiction and fear. Nat Rev Neurosci 14:743-754. CrossRef Medline

Cruz FC, Babin KR, Leao RM, Goldart EM, Bossert JM, Shaham Y, Hope BT (2014) Role of nucleus accumbens shell neuronal ensembles in contextinduced reinstatement of cocaine-seeking. J Neurosci 34:7437-7446. CrossRef Medline

Cruz FC, Javier Rubio F, Hope BT (2015) Using c-fos to study neuronal ensembles in corticostriatal circuitry of addiction. Brain Res 1628:157173. CrossRef Medline

Dai Y, Carlin KP, Li Z, McMahon DG, Brownstone RM, Jordan LM (2009) Electrophysiological and pharmacological properties of locomotor activity-related neurons in cfos-EGFP mice. J Neurophysiol 102:33653383. CrossRef Medline

Dalley JW, Cardinal RN, Robbins TW (2004) Prefrontal executive and cognitive functions in rodents: neural and neurochemical substrates. Neurosci Biobehav Rev 28:771-784. CrossRef Medline

Darcq E, Warnault V, Phamluong K, Besserer GM, Liu F, Ron D (2015) MicroRNA-30a-5p in the prefrontal cortex controls the transition from moderate to excessive alcohol consumption. Mol Psychiatry 20:1261. CrossRef Medline

Dayas CV, Liu X, Simms JA, Weiss F (2007) Distinct patterns of neural activation associated with ethanol seeking: effects of naltrexone. Biol Psychiatry 61:979-989. CrossRef Medline

Dudek M, Abo-Ramadan U, Hermann D, Brown M, Canals S, Sommer WH, Hyytiä P (2015) Brain activation induced by voluntary alcohol and saccharin drinking in rats assessed with manganese-enhanced magnetic resonance imaging. Addict Biol 20:1012-1021. CrossRef Medline

Epstein DH, Preston KL, Stewart J, Shaham Y (2006) Toward a model of drug relapse: an assessment of the validity of the reinstatement procedure. Psychopharmacology (Berl) 189:1-16. CrossRef Medline

Flagel SB, Akil H, Robinson TE (2009) Individual differences in the attribution of incentive salience to reward-related cues: implications for addiction. Neuropharmacology 56 [Suppl. 1]:139-148. CrossRef Medline

Gabbott PL, Warner TA, Jays PR, Salway P, Busby SJ (2005) Prefrontal cortex in the rat: projections to subcortical autonomic, motor, and limbic centers. J Comp Neurol 492:145-177. CrossRef Medline

Hamm JP, Peterka DS, Gogos JA, Yuste R (2017) Altered cortical ensembles in mouse models of schizophrenia. Neuron 94:153-167.e8. CrossRef Medline

Hebb DO (1949) The organization of behavior: a neuropsychological theory. New York, NY: Wiley.

Heidbreder CA, Groenewegen HJ (2003) The medial prefrontal cortex in the rat: evidence for a dorso-ventral distinction based upon functional and anatomical characteristics. Neurosci Biobehav Rev 27:555-579. CrossRef Medline

Heilig M, Barbier E, Johnstone AL, Tapocik J, Meinhardt MW, Pfarr S, Wahlestedt C, Sommer WH (2017) Reprogramming of mPFC transcriptome and function in alcohol dependence. Genes Brain Behav 16:86-100. CrossRef Medline

Hodos W (1961) Progressive ratio as a measure of reward strength. Science 134:943-944. CrossRef Medline

Holtmaat A, Caroni P (2016) Functional and structural underpinnings of neuronal assembly formation in learning. Nat Neurosci 19:1553-1562. CrossRef Medline

Hurley KM, Herbert H, Moga MM, Saper CB (1991) Efferent projections of the infralimbic cortex of the rat. J Comp Neurol 308:249-276. CrossRef Medline

Jurado J, Fuentes-Almagro CA, Prieto-Alamo MJ, Pueyo C (2007) Alternative splicing of c-fos pre-mRNA: contribution of the rates of synthesis and degradation to the copy number of each transcript isoform and detection of a truncated c-Fos immunoreactive species. BMC Mol Biol 8:83. CrossRef

Koya E, Golden SA, Harvey BK, Guez-Barber DH, Berkow A, Simmons DE, Bossert JM, Nair SG, Uejima JL, Marin MT, Mitchell TB, Farquhar D, Ghosh SC, Mattson BJ, Hope BT (2009) Targeted disruption of cocaineactivated nucleus accumbens neurons prevents context-specific sensitization. Nat Neurosci 12:1069-1073. CrossRef Medline 
Laiho JE, Oikarinen M, Richardson SJ, Frisk G, Nyalwidhe J, Burch TC, Morris MA, Oikarinen S, Pugliese A, Dotta F, Campbell-Thompson M, Nadler J, Morgan NG, Hyöty H (2016) Relative sensitivity of immunohistochemistry, multiple reaction monitoring mass spectrometry, in situ hybridization and PCR to detect coxsackievirus B1 in A549 cells. J Clin Virol 77:21-28. CrossRef Medline

Lenoir M, Serre F, Cantin L, Ahmed SH (2007) Intense sweetness surpasses cocaine reward. PLoS One 2:e698. CrossRef Medline

Lin D, Boyle MP, Dollar P, Lee H, Lein ES, Perona P, Anderson DJ (2011) Functional identification of an aggression locus in the mouse hypothalamus. Nature 470:221-226. CrossRef Medline

Madsen HB, Ahmed SH (2015) Drug versus sweet reward: greater attraction to and preference for sweet versus drug cues. Addict Biol 20:433-444. CrossRef Medline

Marchant NJ, Kaganovsky K, Shaham Y, Bossert JM (2015) Role of corticostriatal circuits in context-induced reinstatement of drug seeking. Brain Res 1628:219-232. CrossRef Medline

Martin-Fardon R, Weiss F (2013) Modeling relapse in animals. Curr Top Behav Neurosci 13:403-432. CrossRef Medline

Meinhardt MW, Hansson AC, Perreau-Lenz S, Bauder-Wenz C, Stählin O, Heilig M, Harper C, Drescher KU, Spanagel R, Sommer WH (2013) Rescue of infralimbic mGluR2 deficit restores control over drug-seeking behavior in alcohol dependence. J Neurosci 33:2794-2806. CrossRef Medline

Molyneaux BJ, Arlotta P, Menezes JR, Macklis JD (2007) Neuronal subtype specification in the cerebral cortex. Nat Rev Neurosci 8:427-437. CrossRef Medline

Moorman DE, Aston-Jones G (2015) Prefrontal neurons encode contextbased response execution and inhibition in reward seeking and extinction. Proc Natl Acad Sci U S A 112:9472-9477. CrossRef Medline

Morgan JI, Curran T (1991) Stimulus-transcription coupling in the nervous system: involvement of the inducible proto-oncogenes fos and jun. Annu Rev Neurosci 14:421-451. CrossRef Medline

Noori HR, Cosa Linan A, Spanagel R (2016) Largely overlapping neuronal substrates of reactivity to drug, gambling, food and sexual cues: a comprehensive meta-analysis. Eur Neuropsychopharmacol 26:1419-1430. CrossRef Medline

Noori HR, Schöttler J, Ercsey-Ravasz M, Cosa-Linan A, Varga M, Toroczkai Z, Spanagel R (2017) A multiscale cerebral neurochemical connectome of the rat brain. PLoS Biol 15:e2002612. CrossRef Medline

Paxinos G, Watson C (1998) The rat brain in stereotaxic coordinates. San Diego, CA: Academic.

Peters J, Kalivas PW, Quirk GJ (2009) Extinction circuits for fear and addiction overlap in prefrontal cortex. Learn Mem 16:279-288. CrossRef Medline

Pfarr S, Meinhardt MW, Klee ML, Hansson AC, Vengeliene V, Schönig K, Bartsch D, Hope BT, Spanagel R, Sommer WH (2015) Losing control: excessive alcohol seeking after selective inactivation of cue-responsive neurons in the infralimbic cortex. J Neurosci 35:10750-10761. CrossRef Medline

Richardson NR, Roberts DC (1996) Progressive ratio schedules in drug selfadministration studies in rats: a method to evaluate reinforcing efficacy. J Neurosci Methods 66:1-11. CrossRef Medline

Riga D, Matos MR, Glas A, Smit AB, Spijker S, Van den Oever MC (2014) Optogenetic dissection of medial prefrontal cortex circuitry. Front Syst Neurosci 8:230. CrossRef Medline

Rushworth MF, Noonan MP, Boorman ED, Walton ME, Behrens TE (2011) Frontal cortex and reward-guided learning and decision-making. Neuron 70:1054-1069. CrossRef Medline

Sanchis-Segura C, Spanagel R (2006) Behavioural assessment of drug reinforcement and addictive features in rodents: an overview. Addict Biol 11:2-38. CrossRef Medline
Schwindel CD, McNaughton BL (2011) Hippocampal-cortical interactions and the dynamics of memory trace reactivation. Prog Brain Res 193:163177. CrossRef Medline

Seamans JK, Lapish CC, Durstewitz D (2008) Comparing the prefrontal cortex of rats and primates: insights from electrophysiology. Neurotox Res 14:249-262. CrossRef Medline

Sheng M, Greenberg ME (1990) The regulation and function of c-fos and other immediate early genes in the nervous system. Neuron 4:477-485. CrossRef Medline

Sommer W, Rimondini R, O'Connor W, Hansson AC, Ungerstedt U, Fuxe K (1996) Intrastriatally injected c-fos antisense oligonucleotide interferes with striatonigral but not striatopallidal gamma-aminobutyric acid transmission in the conscious rat. Proc Natl Acad Sci U S A 93:14134-14139. CrossRef Medline

Spanagel R (2000) Recent animal models of alcoholism. Alcohol Res Health 24:124-131. Medline

Strömberg I, Hansson AC, Rimondini R, Sommer W (2004) c-fos antisense oligonucleotides increase firing rate of striatal neurons in the anaesthetized rat. Brain Res 1000:192-194. CrossRef Medline

Suto N, Laque A, De Ness GL, Wagner GE, Watry D, Kerr T, Koya E, Mayford MR, Hope BT, Weiss F (2016) Distinct memory engrams in the infralimbic cortex of rats control opposing environmental actions on a learned behavior. Elife 5:e21920. CrossRef Medline

Tang YY, Tang R (2013) Ventral-subgenual anterior cingulate cortex and self-transcendence. Front Psychol 4:1000. CrossRef Medline

Tang YY, Ma Y, Fan Y, Feng H, Wang J, Feng S, Lu Q, Hu B, Lin Y, Li J, Zhang Y, Wang Y, Zhou L, Fan M (2009) Central and autonomic nervous system interaction is altered by short-term meditation. Proc Natl Acad Sci U S A 106:8865-8870. CrossRef Medline

Tonegawa S, Pignatelli M, Roy DS, Ryan TJ (2015) Memory engram storage and retrieval. Curr Opin Neurobiol 35:101-109. CrossRef Medline

Uylings HB, Groenewegen HJ, Kolb B (2003) Do rats have a prefrontal cortex? Behav Brain Res 146:3-17. CrossRef Medline

Vazdarjanova A, McNaughton BL, Barnes CA, Worley PF, Guzowski JF (2002) Experience-dependent coincident expression of the effector immediate-early genes arc and homer la in hippocampal and neocortical neuronal networks. J Neurosci 22:10067-10071. Medline

Vertes RP (2004) Differential projections of the infralimbic and prelimbic cortex in the rat. Synapse 51:32-58. CrossRef Medline

Warren BL, Mendoza MP, Cruz FC, Leao RM, Caprioli D, Rubio FJ, Whitaker LR, McPherson KB, Bossert JM, Shaham Y, Hope BT (2016) Distinct fos-expressing neuronal ensembles in the ventromedial prefrontal cortex mediate food reward and extinction memories. J Neurosci 36:6691-6703. CrossRef Medline

Westbrook C, Creswell JD, Tabibnia G, Julson E, Kober H, Tindle HA (2013) Mindful attention reduces neural and self-reported cue-induced craving in smokers. Soc Cogn Affect Neurosci 8:73-84. CrossRef Medline

Whiteford HA, Degenhardt L, Rehm J, Baxter AJ, Ferrari AJ, Erskine HE, Charlson FJ, Norman RE, Flaxman AD, Johns N, Burstein R, Murray CJ, Vos T (2013) Global burden of disease attributable to mental and substance use disorders: findings from the global burden of disease study 2010. Lancet 382:1575-1586. CrossRef Medline

Wood JN, Grafman J (2003) Human prefrontal cortex: processing and representational perspectives. Nat Rev Neurosci 4:139-147. CrossRef Medline

Zahr NM, Kaufman KL, Harper CG (2011) Clinical and pathological features of alcohol-related brain damage. Nat Rev Neurol 7:284-294. CrossRef Medline

Zeidan F, Emerson NM, Farris SR, Ray JN, Jung Y, McHaffie JG, Coghill RC (2015) Mindfulness meditation-based pain relief employs different neural mechanisms than placebo and sham mindfulness meditation-induced analgesia. J Neurosci 35:15307-15325. CrossRef Medline 